\title{
Fatores de caracterização da educação não formal: uma revisão da literatura'
}

\author{
Joana Brás Varanda Marques" \\ Denise de Freitas"
}

I- Pesquisa parcialmente financiada pela Fundação de Amparo à Pesquisa do Estado de São Paulo (Fapesp) - processo n ${ }^{0}$ 2012/23088-8. Artigo adaptado parcialmente de dissertação de mestrado. II- Universidade Federal de São Carlos, São Carlos, SP, Brasil. Contatos: joana.bvm@gmail.com; dfreitas@ufscar.br

\section{Resumo}

0 presente artigo relata os resultados de uma investigação de caráter documental, na área da educação não formal. A educação não formal é uma área em expansão, à qual tem sido dada crescente atenção e importância. No entanto, é um setor do conhecimento, em geral, mal definido e ambíguo, no sentido em que os termos empregados são polissêmicos e não há consenso sobre seus usos e definições. Assim, com o objetivo de clarifıcar as definições das diferentes tipologias educativas, incluindo a educação não formal, perguntamos: que características têm estas tipificações educativas? Que critérios ou fatores são utilizados na literatura para defıni-las? Com vista a responder a estas questões de pesquisa, realizamos uma revisão da literatura, analisando 28 documentos, entre literatura nacional e internacional, valendo-nos de técnicas de análise documental e análise de conteúdo. Apuramos que, na maioria da literatura nacional, a terminologia educação formal - não formal informal é a mais utilizada. Confırmamos a dificuldade em se definir e estabelecer fronteiras entre as diferentes tipologias educativas e sublinhamos que as definições das mesmas envolvem um número elevado de fatores de diferentes naturezas. Investigamos 21 fatores usados nas caracterizações das diferentes tipologias educativas, divididos por quatro dimensões de análise: estrutura, processos, propósitos e conteúdos. Apuramos que, apesar da diversidade de fatores utilizados nas definições, há um núcleo adotado com mais frequência, associado principalmente a características estruturais, como localização, grau de planejamento ou duração da aprendizagem.

\section{Palavras-chave}

Educação não formal - Tipologias educativas - Revisão da literatura. 


\title{
Characterization factors of non-formal education: a literature review'
}

\author{
Joana Brás Varanda Marques"
}

Denise de Freitas"

I- Research partially funded by São Paulo Research Foundation (FAPESP - number 2012 / 23088-8). Article partially adapted from master thesis.

II- Universidade Federal de São Carlos,

São Carlos, SP, Brasil.

Contacts: joana.bvm@gmail.com;

dfreitas@ufscar.br

\begin{abstract}
This article reports the results of a document analysis in the field of non-formal education. Non-formal education is a growing area, which has been given increasing attention and importance. However, in general, it is an ill-defined and ambiguous sector of knowledge in the sense that the terms used are polysemic and there is no consensus on their uses and definitions. In order to clarify the definitions of the different education typologies, including non-formal education, we asked: What characteristics do these education typologies have? What criteria or factors are used in the literature to define them? In order to answer these research questions, we conducted a literature review analyzing 28 national and international documents, by means of documentary analysis and content analysis techniques. We found that most of the national literature uses the terminology formal, non-formal, informal education. We confirmed the difficulty in defining and establishing boundaries between different education typologies and highlighted that their definitions involve a large number of factors of different natures. We investigated 21 factors used in the characterization of the different education typologies, divided into four analytical dimensions - structure, processes, purpose and content. We found that, despite the diversity of factors used in the definitions, a core set is adopted more often, associated mainly to structural characteristics, such as location, degree of planning, or duration of learning.
\end{abstract}

\section{Keywords}

Non-formal education - Educational typologies - Literature review. 


\section{Introdução}

É sabido que,

[...] a aprendizagem formal tem dominado

o pensamento político, modelando as formas como são ministradas a Educação e a formação e influenciando as percepções dos indivíduos do que é importante em termos de aprendizagem. (UNIÃo EUROPEIA, 2000, p. 9).

Mas apesar do descuido e da pouca valorização dos setores em que se desenvolve a educação não formal (FALK, 2002), essa área tem crescido de importância nas últimas décadas em todo o mundo (GADOTTI, 2005), à medida que vai se tornando evidente que uma parte substancial da aprendizagem dos indivíduos tem lugar fora do sistema escolar tradicional (FALK, 2002).

0 termo educação não formal começou a ser usado nos finais da década de 1960, numa época de conjeturas políticas e sociais propícias à criação de novos espaços educativos (BELLE, 1982). Assim, "começava a tomar corpo outro setor da Educação que se deslocava da formalidade da escola, reconhecidamente em crise" (CAZELLI; COSTA; MAHOMED, 2010, p. 584). As publicações de Coombs, de 1968, e da Unesco (Organização das Nações Unidas para a Educação, Ciência e Cultura), de 1972, - esta última sobre aprendizagem ao longo da vida -, são pioneiras no uso do termo e na proposta de divisão do sistema educativo em três categorias: formal (F), não formal (NF) e informal (INF) (CAZELLI; COSTA; MAHOMED, 2010). Tal concretização foi um marco importante pois,

[...] apesar de sempre ter sido dada alguma atenção à educação fora da escola e haver reconhecimento da importância dos recursos de ensino e aprendizagem da comunidade, o novo termo 'não formal' ajudou a legitimar esta atenção (BELLE, 1982, p. 160).
Mas apesar de estes conceitos e categorizações dos sistemas educativos terem mais de quarenta anos, estão longe de estar estabilizados ou de serem consensuais. Os termos são polissêmicos, havendo dificuldade em os defınir e diferenciar (COLLEY; HODKINSON; MALCOM, 2002) e ainda se encontram variações nas terminologias usadas.

Para além de as definições não serem consensuais, elas também não são estanques. Por um lado, muitas vezes há sobreposição entre os diferentes modos educativos, por outro, as suas diferentes dimensões se interpenetram e os limites entre cada uma são dependentes das situações e contextos específicos (PASSOS; ARRUDA; ALVES, 2012). Por essas e outras razões, vários autores têm sugerido que se olhe para os diferentes tipos como parte de um continuum, no qual cada situação particular se posiciona (MARANDINO, 2008). Ainda assim, não esqueçamos que, apesar de que cada caso particular possa ser diferente e único e de que entre estas definições existe um continuum de possibilidades, achamos fundamental que nele existam esses três pilares, como "tipos ideais", a partir dos quais pensamos, posicionamos e definimos cada caso concreto.

Mas que características têm essas tipificações educativas? Que critérios devem ser utilizados ou são utilizados na literatura para defini-las?

De modo a responder a essas questões realizamos uma revisão da literatura da área, cujos resultados aqui apresentamos. Buscamos investigar quais os termos usados para distinguir as tipologias educativas e quais as características utilizadas para descrevê-las e defini-las. Fizemos esse estudo por meio da análise de 21 fatores agrupados em quatro dimensões distintas, referentes aos processos educativos.

Como lembra Gohn (2014, p. 48):

A educação não formal ainda não está bem consolidada, não é um conceito, mas todas as categorias e conceitos se estabelecem em um campo de disputas pelo significado 
e demarcação do campo de atuação. [...] Ou seja, por detrás de cada uma dessas terminologias, certamente há autores referenciais, há uma forma de ver o mundo, uma forma de conceber o processo de mudança e transformação social, e como a educação se insere nestas visões. À medida que ficam mais claras essas construções, serão mais saudáveis os debates e os embates sobre essas formulações.

Procuramos, assim, por meio dessa revisão da literatura, contribuir para o esclarecimento das definições envolvidas e consolidação das áreas educativas que vão para além do sistema escolar formal.

\section{Como construímos o estudo de revisão}

Esta pesquisa, por ser do tipo revisão da literatura, se vale de metodologias de análise documental e de análise de conteúdo, com base principalmente nos trabalhos de Krippendorff (1980) e Bardin (2004).

Krippendorff (1980, p. 18) define análise de conteúdo como "[...] uma técnica de pesquisa que serve para fazer inferências replicáveis e válidas a partir de textos (ou outros materiais com significado)" e Bardin (2004, p. 37) completa que se trata de

[...] um conjunto de técnicas de análise das comunicações visando obter, por procedimentos, sistemáticos e objetivos de descrição do conteúdo das mensagens, indicadores (quantitativos ou não) que permitam a inferência de conhecimentos relativos às condições de produção/recepção (variáveis inferidas) destas mensagens.

As análises de conteúdo que fizemos são do tipo categorial, pois agrupamos e classificamos os elementos de significação presentes nos textos, alocando-os em categorias, construindo uma espécie de taxonomia de temas (BARDIN, 2004). Mais especificamente, "dissecamos" as diferentes tipologias de educação, dividindo as suas definições por dimensões e fatores dentro dessas dimensões, como veremos em seguida. Esta categorização foi feita, quase em sua totalidade, a priori, com base na literatura.

\section{A escolha dos fatores e dimensões}

$\mathrm{Na}$ literatura, diferentes autores elegem conjuntos variados de fatores como fundamentais para a caracterização e distinção das tipologias educativas. Há aqueles que elegem apenas alguns para essa caracterização, como Trilla (1998), que usa apenas dois critérios de distinção: um metodológico (escolar vs não escolar) e outro estrutural (educação orientada para a obtenção de títulos acadêmicos ou não) (CAZELLI; COSTA, MAHOMED, 2010), ou como Sefton-Green (2004), que propõe que a separação seja feita entre a organização da aprendizagem (organizada vs acidental, casual) ou pelas estruturas de apoio (por exemplo, escolas, museus, famílias). Há ainda autores que põem a tônica na localização (espaço escolar vs espaço não escolar) e outros, como nós, que pensam que a distinção deve ser feita em mais características, naturalmente, interligadas. Colley, Hodkinson e Malcom (2002), ao fazerem uma revisão da literatura sobre essa temática, encontraram vinte destes fatores. Nesta pesquisa, os utilizamos como base para a caracterização dos três tipos de sistema educativo. Porém, ao longo da análise fizemos algumas adequações e acabamos configurando um conjunto de 21 fatores, listados no Quadro 1, que consideramos abarcar todas as características referidas na literatura consultada. 
Quadro 1 - Fatores de caracterização das tipologias educativas.

\begin{tabular}{|c|c|}
\hline FATORES DE CARACTERIZAÇÃO & FATORES DE CARACTERIZAÇÃO \\
\hline 1 - Relação professor-aluno & 12 - Grau de planejamento e de estrutura \\
\hline 2 - Avaliação & 13 - Determinação dos objetivos e resultados \\
\hline 3 - Aprendizagem coletiva ou individual & 14 - Duração/tempos da aprendizagem \\
\hline 4 - Abordagem pedagógica & 15 - Tipos de grupos \\
\hline 5 - Mediação da aprendizagem & 16 - Intencionalidade do professor/aluno \\
\hline 6 - Aprendizagem tácita ou explícita & 17 - Certificação \\
\hline 7 - Aprendizagem contextual ou generalizável & 18 - Interesses endereçados \\
\hline 8 - Papel das emoções na aprendizagem & 19 - Objetivos da aprendizagem \\
\hline 9 - Natureza e tipo do conhecimento & 20 - Estatuto educativo \\
\hline 10 - Estatuto do conhecimento & 21 - Medição dos resultados \\
\hline 11 - Localização & \\
\hline
\end{tabular}

Pela lista acima apresentada, ficou evidenciado que os fatores são de diferentes naturezas e, por isso, consideramos necessário agrupá-los para se ter um panorama mais esclarecedor. A literatura oferece também algumas soluções para esse agrupamento. Por exemplo, Gohn (2006a) faz a discussão em torno de quem educa, onde educa, como educa, por que educa e para que educa; Marandino (2008) separa os critérios em propósitos, organização do conhecimento, tempo, estrutura, controle e intencionalidade. Nesta pesquisa, iremos usar novamente como referência Colley, Hodkinson e Malcom (2002), que propõem a discussão das tipologias educativas em torno de quatro dimensões: processo, conteúdo, estrutura e propósito. É em torno dessas quatro dimensões que apresentaremos e discutiremos as definições da educação formal, não formal e informal.

\section{A escolha dos documentos a analisar}

0 corpus desta análise foi constituído por um conjunto de 28 documentos (listados no Quadro 2 apresentado abaixo) que, em maior ou menor extensão, definem e tipificam as diferentes aprendizagens e/ou educações. Esses documentos foram selecionados com base na conjugação de vários critérios, procurando que o corpus incluísse:

i) publicações de autores diferentes;

ii) publicações cuja principal preocupação ou foco era a definição da NF, ou sua diferenciação das outras tipologias;

iii) publicações que usassem diferentes terminologias, como NF, aprendizagem ao longo da vida, informal, aprendizagem de livre escolha; iv) publicações que pensassem a educação não formal e afins em diferentes contextos, como abordagens mais voltadas para a pedagogia social, para a educação em países emergentes, para a aprendizagem em museus ou revisões da literatura;

v) publicações oriundas de instituições de referência na regulamentação da educação (Unesco, Comissões de Educação da UE etc.); vi) publicações que abrangessem o principal período em que esta temática tem sido refletida e investigada (principalmente da década de 80 do século passado até a atualidade);

vii) publicações com aceitação da comunidade científica, medida pelo número de citações ${ }^{1} \mathrm{e}$ por referências em outros artigos da área de educação não formal e afins;

1- http://scholar.google.com.br/ 
viii) publicações internacionais (INT) e nacionais (NAC);

ix) publicações oriundas de fontes diversas, como artigos de revistas científicas (ART), livros (LIV), relatórios (REL) ou artigos em conferências (CONF).

Com a utilização da conjugação destes critérios procuramos fazer uma caracterização ampla das diferentes tipologias educativas. Não é nosso objetivo fazer um estado da arte exaustivo ou uma revisão completa da literatura da área, como se pode observar pelo número de publicações analisadas. Procuramos antes fazer uma escolha de publicações que pudessem ser representativas da área e que, portanto, permitissem observar de maneira abrangente as tendências nas definições por meio da diversidade de fontes consolidadas e crediveis na área da educação não formal e de diferentes vertentes, no âmbito internacional e nacional e ao longo das últimas décadas.

Quadro 2 - Publicações analisadas

\begin{tabular}{|c|c|c|c|c|}
\hline REF & FONTE & TERMINOLOGIA & TIPO & ORIGEM \\
\hline a & Rennie, Stocklmayer, 2003 & FORMAL - INFORMAL & ART & INT \\
\hline$b$ & Alves, Passos, Arruda, 2010 & FORMAL - NÃO FORMAL - INFORMAL & ART & NAC \\
\hline C & Passos, Arruda, Alves, 2012 & FORMAL - NÃO FORMAL - INFORMAL & ART & NAC \\
\hline$d$ & Bizerra, Marandino, 2009 & FORMAL - APREND. MUSEUS - LIVRE-ESCOLHA & CONF & NAC \\
\hline e & Gohn, 2006 & FORMAL - NÃO FORMAL - INFORMAL & CONF & NAC \\
\hline$f$ & Anderson, Lucas, Ginns, 2003 & FORMAL - INFORMAL & ART & INT \\
\hline g & Belle, 1982 & FORMAL - NÃO FORMAL - INFORMAL & ART & INT \\
\hline $\mathrm{h}$ & Brennan, 1997 & FORMAL - NÃO FORMAL - INFORMAL & ART & INT \\
\hline $\mathrm{i}$ & Etllng, 1993 & FORMAL - NÃO FORMAL - INFORMAL & ART & INT \\
\hline j & Chagas, 1993 & FORMAL - NÃO FORMAL - INFORMAL & ART & INT \\
\hline $\mathrm{k}$ & Wellington, 1990 & FORMAL - INFORMAL & ART & INT \\
\hline I & Falk, 2002 & FORMAL - TRABALHO - LIVRE-ESCOLHA & ART & INT \\
\hline $\mathrm{m}$ & Rodari, 2009 & FORMAL - INFORMAL & ART & INT \\
\hline$n$ & Griffin, 1994 & FORMAL - INFORMAL & ART & INT \\
\hline 0 & Marsick, Watkins, 2001 & FORMAL - INFORMAL - INCIDENTAL & ART & INT \\
\hline $\mathrm{p}$ & Gadotti, 2005 & FORMAL - NÃO FORMAL - INFORMAL & CONF & NAC \\
\hline q & Eshach, 2007 & FORMAL - NÃO FORMAL - INFORMAL & ART & INT \\
\hline r & Martin, 2004 & FORMAL - INFORMAL & ART & INT \\
\hline $\mathrm{s}$ & Resnick, 1987 & IN SCHOOL - OUT OF SCHOOL & ART & INT \\
\hline $\mathrm{t}$ & Cazelli, Costa, Mahomed, 2010 & FORMAL - NÃO FORMAL - INFORMAL & ART & NAC \\
\hline u & Heimlich, 1993 & FORMAL-NÃO FORMAL-INFORMAL-SELF-DIRECTED & REL & INT \\
\hline v & Marandino, 2008 & FORMAL - NÃO FORMAL - INFORMAL & LIV & NAC \\
\hline w & União Europeia, 2000 & FORMAL - NÃO FORMAL - INFORMAL & REL & INT \\
\hline$x$ & $\begin{array}{c}\text { Ramey-Gassert, Walberg, Walberg, } \\
1994\end{array}$ & FORMAL - INFORMAL & ART & INT \\
\hline y & Colley, Hodkinson, Malcom, 2002 & FORMAL - NÃO FORMAL - INFORMAL & REL & INT \\
\hline z & McCallei et al., 2009 & FORMAL - INFORMAL & REL & INT \\
\hline aа & Eraut, 2000 & FORMAL - NÃO FORMAL & ART & INT \\
\hline$a b$ & Unesco, 2011 & FORMAL - NÃO FORMAL - INFORMAL - INCIDENTAL & REL & INT \\
\hline
\end{tabular}

Legenda: ART - artigo, CONF - conferência, REL - relatório, LIV - livro; INT - internacional, NAC - nacional.

Fonte: dados da pesquisa. 


\section{O processo de análise}

A análise do corpus se deu em várias etapas:

i) Leitura de cada um dos documentos, para um primeiro reconhecimento de todo o corpus;

ii) Nova leitura de cada documento. Identificação das diferentes terminologias usadas em suas definições;

iii) Alocação das características e definições encontradas a cada uma das dimensões usadas (processo, conteúdo, estrutura e propósito) e, dentro dessas, aos respectivos fatores. Alteração de fatores, se necessário;

iv) Construção de tabela com todas as características referidas de cada um dos 21 fatores finais, para cada tipo de educação (F, NF e INF);

v) Análise estatística simples dos fatores e dimensões.

\section{O que encontramos como resultados}

\section{As terminologias utilizadas na literatura}

Em relação aos termos usados e à origem das publicações, o Quadro 2 apresenta um panorama dos documentos consultados. Há duas principais terminologias utilizadas: uma que dicotomiza educação formal e informal e outra que divide o espectro em três grupos (formal, não formal e informal). É também perceptível que a tríade é preferencialmente adotada na literatura nacional, enquanto que na literatura internacional, apesar de haver mais diversidade, usa-se principalmente a dupla formal-informal. Essa tendência já tinha sido apontada por Marandino (2008).

Mas os termos usados não se esgotam nesses três referidos. Há quem divida os setores educativos em "dentro" e "fora" da escola ou em setor formal, setor do trabalho e setor de livre-escolha ou ainda quem acrescente variações, como a aprendizagem incidental ou a self-directed, sublinhando a importância da intencionalidade.

\section{As características utilizadas nos diferentes fatores}

Em seguida discutiremos as definições de educação formal, não formal e informal encontradas na literatura consultada, com base na descrição de cada um dos fatores usados na caracterização dessas tipologias. Os fatores estarão agrupados nas quatro dimensões utilizadas como referência (processo, conteúdo, estrutura e propósito).

Trata-se da apresentação de uma síntese dos resultados, feita por meio da construção de um metatexto a partir de paráfrases do conteúdo textual original dos autores, mantendo rigorosamente o núcleo de significação das ideias. Todas as características distintas encontradas na análise dos documentos constituintes do corpus estão representadas nesse texto. Porém, como muitas dessas características foram referidas por vários autores optamos por apresentar, a título de exemplificação, apenas alguns desses autores, de modo que o texto não ficasse demasiado carregado de citações. No entanto, no Quadro 3, apresentado a seguir encontram-se resumidas todas as características encontradas na literatura consultada com todas as referências devidamente apontadas.

Acrescentamos que, sempre que as concepções e os comentários expressos forem da nossa autoria, isso está explicitado nesse metatexto.

É importante ainda referir que na maioria dos autores que usam a separação formal - informal encontramos características nas definições de informal que associamos ao não formal da separação tripartida. Essas referências foram colocadas em negrito na coluna da não formalidade do Quadro 3. 


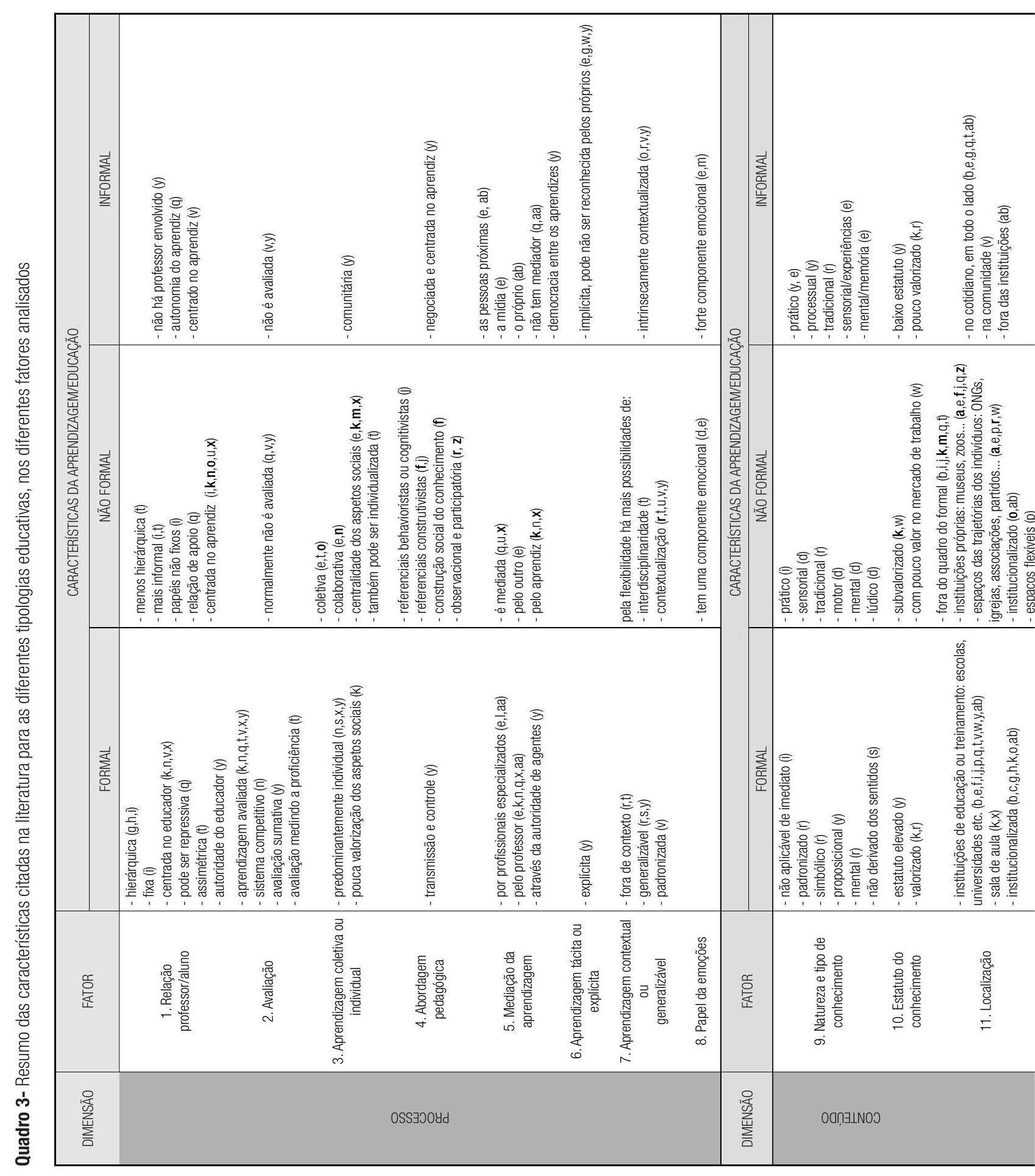




\begin{tabular}{|c|c|c|c|c|c|c|c|c|c|c|c|c|}
\hline 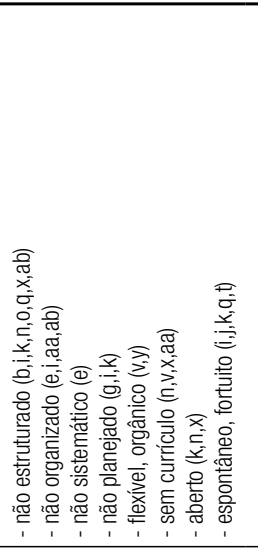 & 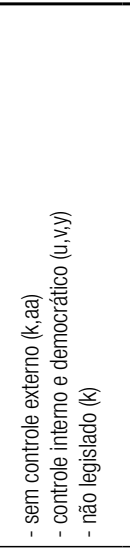 & 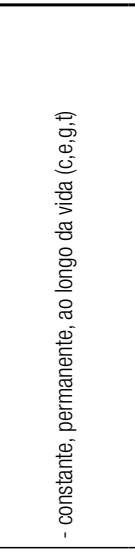 & 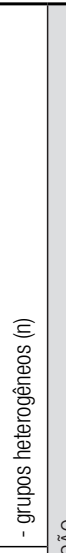 & \multirow[b]{2}{*}{ 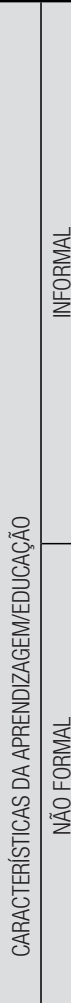 } & 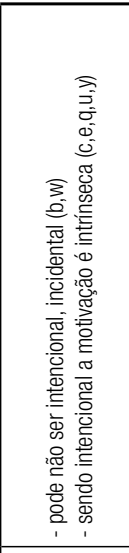 & 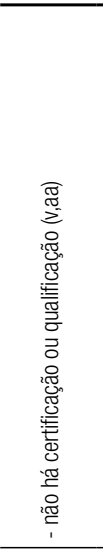 & 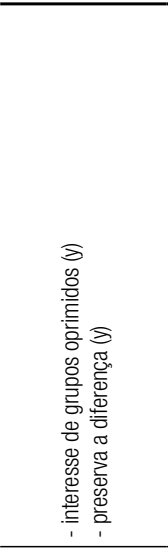 & 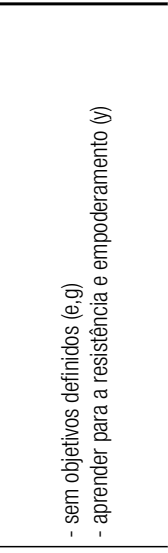 & 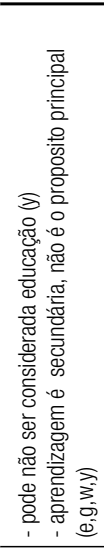 & 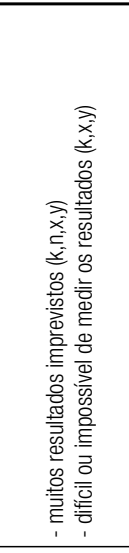 & \multirow{4}{*}{ 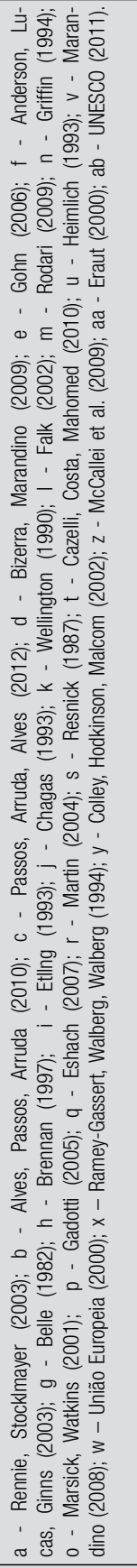 } & \\
\hline 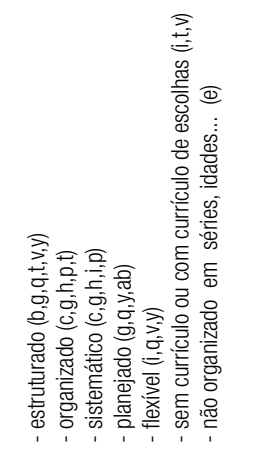 & 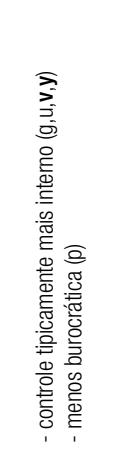 & 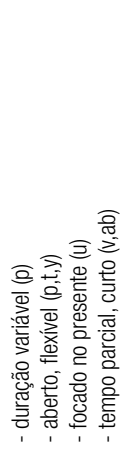 & 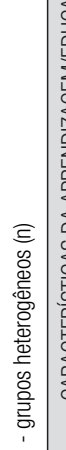 & & 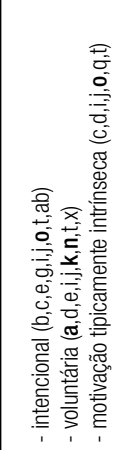 & 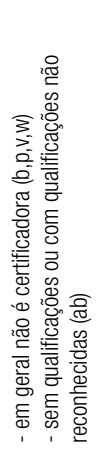 & 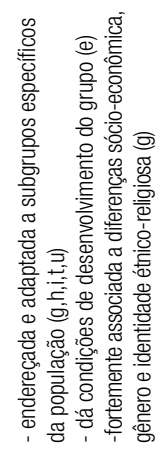 & 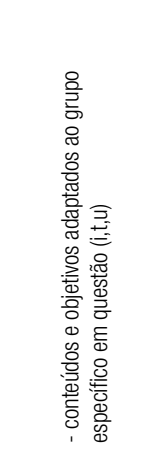 & 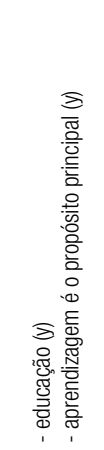 & 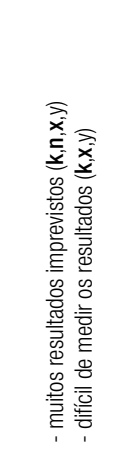 & & 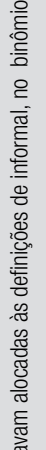 \\
\hline 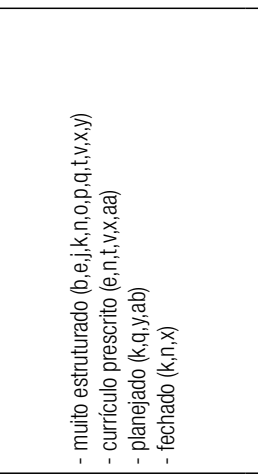 & 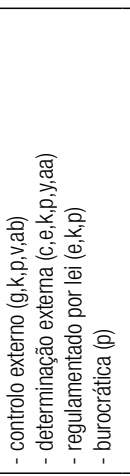 & 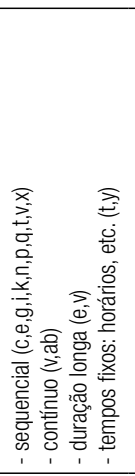 & 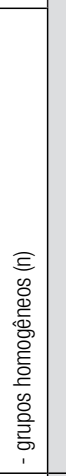 & 竞 & 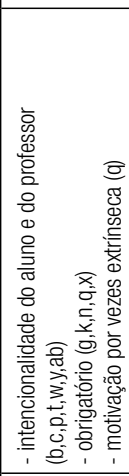 & 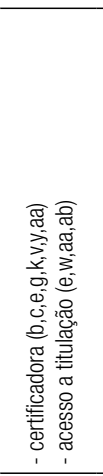 & 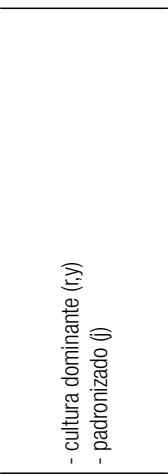 & 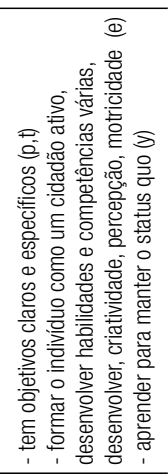 & 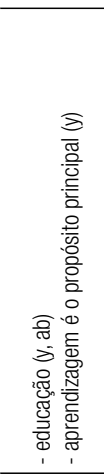 & 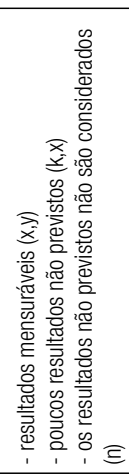 & & 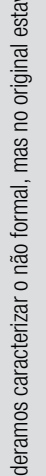 \\
\hline 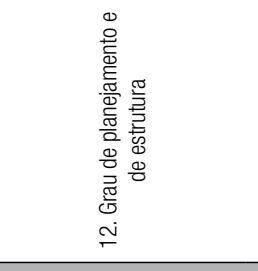 & 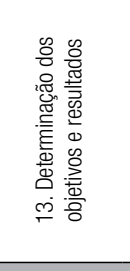 & 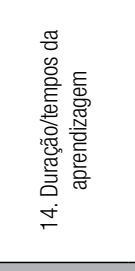 & 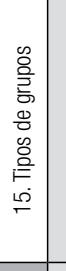 & $\begin{array}{l}\text { 옹 } \\
\text { 采 }\end{array}$ & 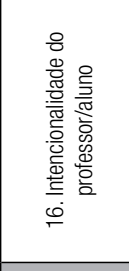 & 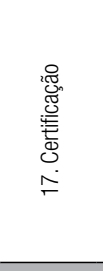 & 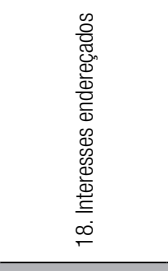 & 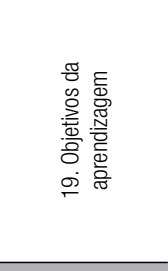 & 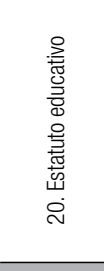 & 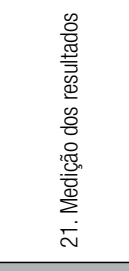 & & \\
\hline 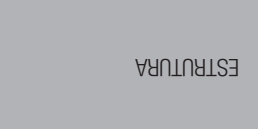 & & & & 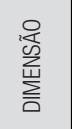 & & & ISC & Odoyd & & & 芴 & \\
\hline
\end{tabular}




\section{Dimensão processo}

Nesta dimensão, encontram-se os fatores relacionados com os aspectos processuais da aprendizagem, nomeadamente as suas características, as relações entre os intervenientes, a avaliação e as abordagens pedagógicas utilizadas.

\section{Fator 1: Relação professor-aluno}

Quando se trata de definir a relação professor-aluno na formal, observam-se dois tipos de caracterizações interligadas: uma se refere à figura central do professor e ao fato de que este é quem guia o processo de aprendizagem; a outra, que em nosso entender talvez seja consequência da primeira, se refere à separação dos papéis de professor e aluno. "Na escola, os papéis aluno-professor [...] são hierarquizados e não se alteram em pouco tempo" (ETLLNG, 1993, p. 73). As relações são assimétricas (CAZELLI; COSTA; MAHOMED, 2010) e podem até ser repressivas, e o professor é a figura de autoridade (COLLEY; HODKINSON; MALCOM, 2002). Na não formal a rigidez esbate-se. A literatura consultada vai na direção de que é mais centrada no aprendiz e que, mesmo quando é guiada ou conduzida por um professor, "evita formalidades e hierarquias" (CAZELLI; COSTA; MAHOMED, 2010, p. 586) e é mais apoiante e solidária. Finalmente, no outro lado do espectro, encontra-se a educação informal, centrada no aluno ou no aprendiz. É ele quem conduz e faz o seu percurso. $\mathrm{Na}$ maioria dos casos, não há professor envolvido (COLLEY; HODKINSON; MALCOM, 2002, p. 16).

\section{Fator 2: Avaliação}

0 ensino formal tem um forte componente avaliativo. Essa avaliação é feita, em geral, "verificando o sucesso desse aprendizado, medindo estatisticamente uma variável latente, usualmente chamada de proficiência" (CAZELLI; COSTA; MAHOMED, 2010, p. 584). Devido, em parte, a essa componente avaliativa, que não é exclusiva aos alunos (escolas, professores e programas também são avaliados) o sistema formal é também competitivo (GRIFFIN, 1994). No caso do não formal, a aprendizagem normalmente não é avaliada, pelo menos não no sentido da avaliação do aprendiz para fins de acreditação (ESHACH, 2007). Em relação ao informal, apesar de poucos autores caraterizarem este fator, são categóricos: não há avaliação (MARANDINO, 2008).

\section{Fator 3: Aprendizagem coletiva ou individual}

Consideramos a aprendizagem como sendo um processo para além de ser um produto. Bizerra e Marandino (2009, p. 5) relatam que enquanto esta é uma ideia

\section{[...] bastante aceita entre os pesquisadores estudados, o mesmo não acontece quando se analisa como esse processo ocorre. Enquanto para alguns autores a aprendizagem é um processo prioritariamente mental, para outros ele é social. (BIZERRA; MARANDINO, 2009, p. 5).}

Concordando com uma ou outra corrente, pensamos que o fato de se dar mais ênfase ao coletivo ou ao indivíduo no contexto da aprendizagem confere características distintas ao processo educativo em causa.

$\mathrm{Na}$ educação formal, apesar de os alunos estarem normalmente divididos em turmas, a aprendizagem é tipicamente individual, assim como as dinâmicas, a avaliação e certificação (RESNICK, 1987). Os aspectos sociais são pouco valorizados (WELLINGTON, 1990). Já na educação não formal, o leque de possibilidades pode ser variado, desde a aprendizagem individualizada à mais coletiva (CAZELLI; COSTA; MAHOMED, 2010). Mas para a maioria dos autores, os aspectos sociais são centrais, trata-se de uma aprendizagem colaborativa. Para Gohn (2006a, p. 3), a educação não formal "[...] situa-se no campo da Pedagogia Social - aquela que trabalha com coletivos e se preocupa com os processos de construção de 
aprendizagens e saberes coletivos" e é importante na formação da identidade do grupo e no desenvolvimento da sua autoestima e valorização. Também a informal depende fortemente das relações sociais e da comunidade (COLLEY; HODKINSON; MALCOM, 2002). Aprendemos no seio da família, no trabalho e em todos os aspectos da nossa vida com as pessoas que nos são próximas. Ainda assim, apesar de não ser referido por ninguém, pensamos poder acrescentar que esta aprendizagem pode ser também individual, quando lemos um livro, navegamos na internet ou assistimos a um documentário na televisão.

\section{Fator 4: Abordagem pedagógica}

Aqui se oscila, segundo Colley, Hodkinson e Malcom (2002), entre uma pedagogia de transmissão e controle no formal e uma pedagogia negociada e centrada no aprendiz no informal. A educação não formal ficaria no meio desses dois extremos, mas sendo "fortemente observacional e participativa” (MARTIN, 2004, p. 74). Ainda em relação ao não formal, há autores que se referem às correntes teóricas mais utilizadas, principalmente no contexto de museus. São elas as correntes behavioristas, cognitivistas, construtivistas e, em geral, teorias que abordam a construção social do conhecimento (CHAGAS, 1993). Mas essas correntes não são exclusivas do não formal, são também a base das abordagens na educação formal. Aliás, muitas vezes os espaços de educação tipicamente não formal (museus e centros de ciências, por exemplo):

[...] partilham formas de organizar as respectivas atividades que se baseiam em princípios pedagógicos consistentes com os princípios pedagógicos que regem muitas das atividades da escola. Tal consistência põe em relevo a continuidade que existe entre a educação formal e a educação não formal. (CHAGAS, 1993, p. 7).

Mas, em nosso entender, se por um lado tal continuidade facilita o diálogo e a colaboração entre as instituições escola e museu, por outro, a "escolarização" que se observa nestes espaços não formais nem sempre é desejável.

Vale acrescentar que no caso de estarmos pensando em aprendizagem veiculada pelas diferentes mídias, não podemos considerar apenas as abordagens pedagógicas, mas também as abordagens comunicacionais.

\section{Fator 5: Mediação da aprendizagem}

$\mathrm{Na}$ educação formal, é muito claro que a mediação é feita pelo professor, que, regra geral, tem um papel central e de destaque no processo (ERAUT, 2000). É ele quem guia e controla a aprendizagem e tem autoridade (COLLEY; HODKINSON; MALCOM, 2002). "A educação formal é o local onde profissionais ajudam a guiar-nos no nosso desenvolvimento" (FALK, 2002, p. 3). Também a não formal é, geralmente, mediada, não por um professor, mas por um outro agente mediador, guia de museu, animador etc. (ESHACH, 2007). Nesse cenário, em geral estamos perante uma "relação entre o aprendiz e o facilitador não hierárquica" (HEIMLICH, 1993, p. 3) ou autoritária. No caso da informal, pode-se dizer que não existe efetivamente a figura do mediador (ERAUT, 2000), apesar de que em alguns casos há pessoas mediando a aprendizagem, mas sem assumir esse papel explicitamente. Esses agentes poderão ser todos, principalmente os mais próximos (família, colegas de escola e de atividades, meios de comunicação de massa etc.) (UNESCO, 2011). 0 papel central é do aluno ou aprendiz e, assim, na maioria dos casos, a aprendizagem é dirigida ou mediada por ele mesmo (ESHACH, 2007).

\section{Fator 6: Aprendizagem tácita ou explícita}

$\mathrm{Na}$ educação formal, a aprendizagem é explícita, pois o foco e a intenção são majoritariamente educativos (COLLEY; HODKINSON; MALCOM, 2002). Apesar de 
não haver autores que caracterizam este fator no caso do não formal, consideramos que é explícita, pelas mesmas razões que o é na educação formal. Já a aprendizagem informal, é muitas vezes tácita e até “pode não ser reconhecida, mesmo pelos próprios indivíduos, como enriquecimento dos seus conhecimentos e aptidões" (UNIÃO EUROPEIA, 2000, p. 9).

\section{Fator 7: Aprendizagem contextual ou generalizável}

A educação formal é tipicamente descontextualizada (CHAGAS, 1993) e, acrescentamos, muitas das críticas e tentativas de se alterar o sistema formal de ensino vão na direção de alterar exatamente essa característica, para que ele se torne menos distante do cotidiano e das experiências dos alunos. A sua ênfase é na linguagem e no simbólico (MARTIN, 2004) e é generalizável, padronizada e acadêmica, o que permite que seja "aplicável numa variedade de contextos" (COLLEY; HODKINSON; MALCOM, 2002, p. 16). Na educação não formal, em tese, “a liberdade na seleção de conteúdos e metodologias amplia as possibilidades de interdisciplinaridade e contextualização" (CAZELLI; COSTA; MAHOMED, 2010, p. 586), possibilitando e facilitando o uso de recursos locais e situações específicas a um determinado grupo (HEIMLICH, 1993). Finalmente, a aprendizagem informal "ocorre onde o significado é intrínseco ao contexto" (MARTIN, 2004, p. 74). Pode ser associada com o que aprendemos no nosso contexto diário de vida (GOHN, 2006a).

\section{Fator 8: Papel das emoções na aprendizagem}

Apesar de pouco referidos na literatura, os aspectos emotivos e seu papel na aprendizagem são cada vez mais valorizados e achamos importante que sejam discutidos. De modo geral e pela análise de outros fatores, como a rigidez e a padronização, podemos considerar que as emoções não são valorizadas na aprendizagem formal. $\mathrm{Na}$ não formal $\mathrm{e}$ informal, alguns autores indicam que elas têm um papel importante, às vezes até central, na motivação e nas escolhas do aprendiz. Por exemplo, referindo-se a centros de ciências, Eshach (2007, p. 178) afirma que "podem gerar maravilhamento, interesse, entusiasmo, motivação e vontade de aprender, sentimentos esses muitas vezes negligenciados na abordagem à ciência na escola formal tradicional". Acrescentamos que o fato de na educação não formal e informal não haver avaliação e a participação ser voluntária possibilita a criação de ambientes de aprendizagem que tendem a ser mais descontraídos, com componentes lúdicos e experimentais que, a nosso ver, poderão ser facilitadores da aprendizagem.

\section{Dimensão conteúdo}

Nesta dimensão, discute-se a natureza do que é ensinado, se o conhecimento é produzido ou apenas transmitido, se o foco é em conhecimento proposicional ou práticas situadas e qual o estatuto do conhecimento.

\section{Fator 9: Natureza e tipos de conhecimento}

A literatura consultada considera que na educação formal o conhecimento é proporcional, generalizável e a aprendizagem "enfatiza valores universais, critérios e padrões de performance" (MARTIN, 2004, p. 75). Normalmente é também um conhecimento com pouca aplicação imediata (ETLLNG, 1993). Acrescentamos que é dividido e compartimentado em disciplinas e transmitido numa lógica de acumulação e aumento gradual de complexidade. A educação formal é também associada a um tipo de conhecimento puramente mental, em que se "introduz novos assuntos, história desconhecida e o universo físico não derivados dos sentidos" (MARTIN, 2004, p. 74). Por outro lado, na educação não formal, o conhecimento é caracterizado como mais prático e a aprendizagem é influenciada "pela percepção, consciência, emoção e memória” (BIZERRA; MARANDINO, 2009, p. 5). É mais provável que envolva componentes físicas, motoras e não 
apenas mentais (RESNICK, 1987) e podemos acrescentar que tem tendência (ou pelo menos mais possibilidade) de ser um conhecimento interdisciplinar e contextualizado. No âmbito informal, o conhecimento é prático e empírico (GOHN, 2006a). Pode ser associado ao senso comum e permite a incorporação de saberes tradicionais (MARTIN, 2004). Não é organizado em disciplinas e a aprendizagem é "um processo indutivo de reflexão e ação" (MARSICK; WATKINS, 2001, p. 28).

\section{Fator 10: Estatuto do conhecimento}

0 conhecimento aprendido e ensinado na educação formal é valorizado, tendo por isso um estatuto elevado. Martin (2004) acrescenta até que nesse contexto é mais importante o conhecimento ensinado do que quem o ensina. Em relação ao contexto não formal, a aprendizagem tem normalmente baixo estatuto e é referido que:

[...] não é habitualmente considerada como 'verdadeira' aprendizagem, nem os seus resultados têm muito valor de troca no mercado de trabalho. A aprendizagem não formal é, por conseguinte, tipicamente subvalorizada. (UNIÃO EUROPEIA, 2000, p. 9).

A informal tende a ser ainda menos valorizada e com estatuto também baixo, uma vez que "não é organizada, os conhecimentos não são sistematizados e são repassados a partir das práticas e experiência anteriores" (GOHN, 2006a, p. 3).

\section{Dimensão estrutura}

A localização física da aprendizagem, os contextos, os tempos, os currículos, objetivos e a certificação entram nesta dimensão que agrega os elementos estruturais e organizacionais. Esta é a dimensão mais comentada e usada na literatura para caracterizar e diferenciar os três tipos educativos.

\section{Fator 11: Localização}

0 fator localização é um dos mais referidos na literatura. Em nosso entender, isso se deve provavelmente ao fato de ser comum traçar as fronteiras entre o espaço escolar e o não escolar ou associar a educação formal à escola e as outras fora dela, por oposição. Mas há vários autores que sublinham que

[...] o espaço físico é insufıciente para definir o carácter das práticas educativas que nele se encerram, visto que as práticas educativas não formais podem ter lugar no espaço físico da escola, assim como as práticas formais podem ocorrer (e de fato ocorrem) em lugares como os museus, tidos como espaços de práticas não formais (CAZELLI; COSTA; MAHOMED, 2010, p. 586).

Então, há que ter em conta um conjunto mais amplo de fatores e ver cada caso como um caso particular. No entanto, pensando em tipologias ideais, a literatura consultada é unânime: a aprendizagem ou educação formal é fornecida por uma instituição de ensino. É “institucionalizada através de organizações públicas e corpos privados reconhecidos que, na sua totalidade, constituem o sistema educativo de um país" (UNESCO, 2011, p. 11). Assim, os pontos principais são a institucionalização e o reconhecimento dessas instituições. Ou seja, essa é a educação que acontece em instituições próprias, construídas para o efeito: escola, universidade (ALVES; PASSOS; ARRUDA, 2010), centros de formação, sala de aula (RAMEY-GASSERT; WALBERG III; WALBERG, 1994). Para a educação não formal, a tendência é definir por exclusão, ou seja, a educação não formal é a que acontece fora da escola, fora dos quadros formais (RODARI, 2009). Mas há também quem a defina de outra maneira, frisando que ela acontece em espaços feitos para o efeito, como museus, zoológicos etc., ou espaços de ações coletivas, que acompanham as trajetórias das pessoas, 
como ONGs ou clubes (CHAGAS, 1993). Assim, apesar de não ocorrer nas instituições escolares, é ainda um tipo de educação institucionalizada (MARSICK; WATKINS, 2001). Mas apesar de ser normalmente oferecida e promovida por uma instituição, há quem sublinhe também a "sua flexibilidade [...] em relação à criação e recriação dos seus múltiplos espaços" (GADOTTI, 2005, p. 2). Já a aprendizagem informal ocorre nas atividades mundanas, no dia a dia, nas aprendizagens no espaço familiar, no meio cotidiano, nas atividades de lazer, na comunidade (GOHN, 2006a). Ela ocorre durante o processo de socialização e por isso ocorre "em todo o lado" (ESHACH, 2007, p. 174).

\section{Fator 12: Grau de planejamento e de estrutura}

Outro fator que é muito referido é a estrutura e planejamento das diferentes tipologias educativas. Também aqui se percebe a tendência e utilidade de se ver as coisas como um contínuo e não como caixas estanques.

0 ensino formal está no extremo da estruturação e planejamento, mas a estruturação mencionada na literatura é diversa. Há referências à estrutura em termos de objetivos de aprendizagem, tempos, organização em turmas e classes, sistematização das atividades, currículos fechados, organização sequencial e programas prescritos (CAZELLI; COSTA; MAHOMED, 2010). Há também referências à hierarquização da estrutura e ao planejamento, ou seja, organização e definição prévia dos objetivos, conteúdos e processos (WELLINGTON, 1990). Resumindo, o ensino formal é definido como sendo estruturado, planejado, fechado, hierarquizado e com um currículo definido (MARANDINO, 2008). No não formal, os autores são também unânimes em afirmar que é uma educação "organizada e sistemática, mas levada a efeito fora do sistema formal" (GADOTTI, 2005, p. 2). É, assim, um tipo de educação também planejada, com objetivos educativos, mas não está organizada de maneira fechada e hierárquica, é mais adaptável e flexível (GADOTTI, 2005). Não tem currículos pré-estabelecidos ou "tende a ter um currículo de escolhas e opções (cafeteria curriculum) em vez do currículo prescrito e sequencial encontrado nas escolas" (ETLLNG, 1993, p. 73). No outro extremo do contínuo, encontra-se a aprendizagem informal. Aqui o mote está na ausência de (ou pouca) estrutura, organização e sistematização (ALVES; PASSOS; ARRUDA, 2010). Não há base institucional ou programática. É flexível, espontânea, "orgânica e em evolução" (COLLEY; HODKINSON; MALCOM, 2002, p. 16), sem currículo ou sequência (RAMEY-GASSERT; WALBERG III; WALBERG, 1994).

\section{Fator 13: Determinação dos objetivos e resultados}

A determinação dos objetivos está relacionada, a nosso ver, com o fato de haver ou não planejamento e estrutura prédeterminada. 0 que esse fator traz de novo é o fato de essa determinação poder, ou não, acontecer na forma de diretrizes nacionais e então haver uma prescrição e uniformização em nível nacional regulamentando os objetivos e até os processos e resultados educativos. 0 caso afirmativo é o que acontece no ensino formal, que se caracteriza por ser legislado, determinado e controlado externamente com regulamentações, leis orgânicas e diretrizes nacionais, em maior ou menor extensão (WELLINGTON, 1990). Ou seja, é de alguma maneira regulamentado, mesmo o privado, tipicamente pelos ministérios e secretarias de educação por meio do estabelecimento de objetivos, resultados, currículos etc. (GADOTTI, 2005). Estas instituições de tutela são também fiscalizadoras do cumprimento das metas estabelecidas (GADOTTI, 2005). Já a educação não formal é muito "mais difusa, menos hierárquica e menos burocrática" (GADOTTI, 2005, p. 2) e normalmente tem pouca influência do governo ou outras autoridades, ou seja, tende a ser controlada e determinada internamente (MARANDINO, 2008), seja pela instituição, 
educadores ou até os aprendizes, não seguindo diretrizes externas mais amplas (BELLE, 1982). Acrescentamos que, em certos casos, pode ser direcionada, por exemplo, por regras de acesso a financiamento público. No caso do informal, "não há especificação externa dos resultados" (ERAUT, 2000, p. 114). É internamente que se definem os objetivos e o controle é democrático, quando não é completamente determinado pelo próprio aprendiz (MARANDINO, 2008).

\section{Fator 14: Duração/tempos da aprendizagem}

0 tempo é também uma variável diferenciadora. A educação formal, que é padronizada e estruturada em termos de conteúdos, espaços e objetivos, também o é, naturalmente, em termos temporais (PASSOS; ARRUDA; ALVES, 2012). É cronologicamente gradual com níveis atingidos hierarquicamente ao longo do tempo (CAZELLI, COSTA, MAHOMED, 2010). Toda ela é controlada temporalmente com os calendários letivos, os horários das aulas e outras atividades etc. (COLLEY; HODKINSON; MALCOM, 2002). 0 tempo é então longo, sequencial, contínuo, fixo e limitado (MARANDINO, 2008). Já a não formal "não é constituída necessariamente por um percurso estruturado e contínuo" (UNESCO, 2011). Além disso, caracteriza-se por ser mais focada no presente e os tempos serem mais curtos e flexíveis (GADOTTI, 2005). Bem diferente das outras tipologias, a informal é um processo permanente, não organizado e que ocorre a todo o momento, na vivência do dia a dia (CAZELLI; COSTA; MAHOMED, 2010).

\section{Fator 15: Tipos de grupos}

Há também na literatura algumas referências aos tipos de grupos de aprendizes nas diferentes educações. Na formal os grupos são muito homogêneos, as turmas são divididas por alunos de mesmo nível, com a mesma idade, estudando o mesmo assunto (GRIFFIN, 1994). Essa divisão se atenua no não formal e informal, em que podemos ter grupos de idades e interesses variados, por exemplo, grupos familiares ou outros grupos heterogêneos que se encontram por partilharem interesse pelos mesmos temas ou atividades (GOHN, 2006a). Mas sublinhamos que há casos de grupos mais homogêneos, principalmente na educação não formal, como visitas de um grupo de alunos a um museu ou uma atividade especialmente direcionada a um determinado grupo social.

\section{Dimensão propósitos}

Esta dimensão se relaciona com os objetivos das diferentes abordagens educativas, em sentido amplo.

\section{Fator 16: Intencionalidade do professor/aluno}

Este também foi um dos fatores mais referidos na literatura consultada. Parece ser ponto importante na distinção entre as educações o fato de elas serem compulsórias ou voluntárias, de livre-escolha.

Começando pela educação formal, na literatura aparecem características em duas direções. Um conjunto de autores caracteriza a educação formal como intencional, no sentido de ser explícito que o objetivo é educativo ou a certificação (UNIÃO EUROPEIA, 2000). Outros autores frisam a obrigatoriedade, ou seja, o fato de esse tipo de educação ser compulsório e que, portanto, "a motivação é muitas vezes extrínseca" (ESHACH, 2007, p. 174) sendo o "controle do professor" (COLLEY; HODKINSON; MALCOM, 2002, p. 16).

Para a maioria dos autores, a educação não formal também se caracteriza pela intencionalidade do aluno em aprender: "Há na educação não formal uma intencionalidade na ação, no ato de participar, de aprender e de transmitir ou trocar saberes" (GOHN, 2006a, p. 3). A grande diferença é que esse tipo de educação, na maioria dos casos, não é compulsória. Baseia-se numa atitude voluntária e, portanto, "a motivação pode ser extrínseca, 
mas é tipicamente mais intrínseca" (ESHACH, 2007, p. 174). 0 aluno escolhe as atividades $\mathrm{e}$ a oferta segundo suas preferências e interesses, sendo assim uma educação centrada no aprendiz (MARANDINO, 2008). 0 fato de não depender de meios ou fins padronizados (BELLE, 1982) lhe confere uma maior liberdade que permite que a intencionalidade não seja só a de aprender, mas também a de aprender o quê e como (RENNIE; STOCKLMAYER, 2003).

A educação informal, "na maioria das vezes é não intencional ou incidental" (PASSOS; ARRUDA; ALVES, 2012, p. 20). Ou seja, é uma educação mais espontânea. 0 grupo de autores que considera que existe também aqui intencionalidade, aproximandose mais da definição de não formal, classifica a motivação como principalmente intrínseca (ETLLNG, 1993).

Esse fator foi o mais difícil de separar nas três categorias. Para um conjunto grande de autores há sempre intencionalidade na aprendizagem, seja qual for o contexto. Para outros, a falta de intencionalidade é o que distingue a aprendizagem informal das outras, podendo até ser também chamada de incidental por esse fato. Parece-nos que por trás da discussão está a ideia de que, no caso da informal, o ato de aprender é um efeito colateral de outras atividades e, muitas vezes, não estamos plenamente conscientes de que o fazemos.

\section{Fator 17: Certificação}

0 ensino formal é por natureza um ensino certificador, que leva a qualificações padronizadas, titulações e diplomas (UNIÃO EUROPEIA, 2000) e que, também por isso, exige certos requisitos de admissão no sistema e avaliações ao longo do percurso acadêmico (CAZELLI; COSTA; MAHOMED, 2010). Já a educação não formal "normalmente leva a qualificações que não são reconhecidas como formais ou equivalentes a qualificações formais pelas autoridades competentes ou não leva a qualificações nenhumas” (UNESCO, 2011, p.11) e, consequentemente, não é, em geral, uma educação certificadora. Por último, a educação informal não tem "necessidade de certificação" (MARANDINO, 2008, p. 15).

Essa questão da acreditação é bastante referida na literatura e de suma importância na discussão educativa atual. Alguns dos relatórios consultados, principalmente ligados a organizações como a Organização para a Cooperação e Desenvolvimento Econômico (OCDE), a Organização das Nações Unidas (ONU) e a União Europeia, focam na definição dos tipos de educação com o propósito de normatizar essas aprendizagens fora da escola, no trabalho ou em outras situações. 0 intuito é de acreditar as aprendizagens, valorizando-as por meio de certifıcação ou equivalência de conhecimentos tácitos e conhecimentos adquiridos em situações não formais e informais. Então, de algum modo, a avaliação e acreditação começam a estar também presentes nesses outros tipos de educação, nem que seja a posteriori. Pensamos que essa tendência deve ser vista com cautela. Apesar de a atenção dada a estes tipos de educação ser benéfica, o desenvolvimento de políticas e regulações das aprendizagens fora do circuito do sistema formal acaba por "formalizar" a educação não formal e informal, ameaçando alterar suas naturezas e, consequentemente, privando a sociedade dos seus benefícios (COLLEY; HODKINSON; MALCOM, 2002).

\section{Fator 18: Interesses endereçados}

As referências a este fator em relação ao ensino formal caracterizam-no como sendo padronizado, com pré-requisitos, controlado politicamente e, indo mais longe, com tendência a servir a "interesses dos grupos poderosos e dominantes" (COLLEY; HODKINSON; MALCOM, 2002, p. 16) e podendo "representar uma cultura que denigre as culturas indigenas” (MARTIN, 2004, p. 74).

Já a educação não formal, devido à sua maior flexibilidade, é especialmente adequada a ir ao encontro de interesses da comunidade 
e de grupos particulares de alunos (GOHN, 2006a; BELLE, 1982). Assim, há a possibilidade de ser direcionada aos interesses de minorias ou de grupos oprimidos. Para Gohn (2006a, p. 4), esse tipo de educação "dá condições aos indivíduos para desenvolverem sentimentos de autovalorização, de rejeição dos preconceitos que lhes são dirigidos, o desejo de lutarem para de ser reconhecidos como iguais (enquanto seres humanos), dentro de suas diferenças (raciais, étnicas, religiosas, culturais etc.)”.

Por outro lado, Belle (1982) lembra uma outra perspectiva:

A educação não formal, talvez em maior medida do que a educação formal, está fortemente associada a diferenças socioeconômicas, de gênero e identidade étnico-religiosa. Entre as crianças e os jovens, são os recursos dos pais que permitem uma escolha entre alternativas de programas que são frequentemente delimitadas por características de gênero e étnico-religiosos. Entre os adultos, alguns tipos de programas, como o planejamento familiar ou de alfabetização, diferenciam claramente as populações em termos de nível socioeconômico. Outros programas, como o treinamento no trabalho são frequentados por diferentes gêneros e classes sociais, dependendo da natureza do treinamento (BELLE, 1982, p. 174).

$\mathrm{Na}$ categoria da educação informal, apenas Colley, Hodkinson, Malcom (2002) se pronunciam, dizendo que esta serve os grupos de oprimidos. Os autores ressalvam que estão a definir tipos ideais em cada fator, mas achamos que pela caracterização de outros fatores, o informal não sendo organizado ou estruturado serve espontaneamente ao interesse de todos os grupos e que é o não formal que pode ter um papel de destaque em serviço dos grupos oprimidos e minorias menos representadas na cultura mainstream da escola formal, como já sublinhado por Gohn (2006a).
Fator 19: Objetivos da aprendizagem

$\mathrm{Na}$ educação formal, os objetivos de aprendizagem estão bem definidos e especificados, nomeadamente por meio de parâmetros curriculares e outras diretrizes educacionais (GADOTTI, 2005), e incluem o

[...] ensino e aprendizagem de conteúdos historicamente sistematizados, normalizados por leis, dentre os quais se destacam o de formar o indivíduo como um cidadão ativo, desenvolver habilidades e competências várias, desenvolver a criatividade, percepção, motricidade etc. (GOHN, 2006a, p. 3).

Numa outra perspectiva, alguns autores afirmam que o objetivo é "aprender para manter o status quo" (COLLEY; HODKINSON; MALCOM, 2002, p. 16).

$\mathrm{Na}$ educação não formal, os objetivos podem ser muito variados. Podem também ser adaptados ao grupo em questão, sendo mais flexíveis (ETLLNG, 1993). Alguns exemplos incluem atividades que buscam "aumentar, ou conscientizar para a solidariedade religiosa e étnica; outras servem para potencializar habilidades para mobilidade socioeconômica e capacitação laboral” (BELLE, 1982, p. 165); e ainda para

[...] a aprendizagem política dos direitos dos indivíduos enquanto cidadãos; [...] e exercício de práticas que capacitam os indivíduos a se organizarem com objetivos comunitários, voltadas para a solução de problemas coletivos cotidianos. (GOHN, 2006a, p. 2).

Numa outra linha, por vezes, os objetivos da educação não formal são traçados em relação à educação formal, ou seja, ela é vista em função do seu papel de complemento, alternativa, adição etc. à educação formal num determinado contexto (BRENNAN, 1997). 
Na educação informal, uma vez que na maioria dos casos a aprendizagem não é programada ou estruturada e os resultados acontecem nos processos de socialização (GOHN, 2006a), pensamos que não se pode efetivamente dizer que há objetivos de aprendizagem definidos. Sendo assim, não concordamos com os autores Colley, Hodkinson, Malcom (2002, p. 16) quando afirmam que o objetivo é "aprender para a resistência e empoderamento". Isso, em nossa opinião, se enquadra nos objetivos da educação não formal, descritos acima.

\section{Fator 20: Estatuto educativo}

0 ensino formal e o não formal têm estatuto de educação, mas, por exemplo, para Colley, Hodkinson, Malcom (2002) o informal não tem. Essa discussão é semelhante à iniciada no fator 16, sobre intencionalidade. Relembramos que o argumento é que a categoria informal é, muitas vezes, não intencional, não estruturada nem planejada e até, em termos de aprendizagem, pouco consciente e espontânea, não devendo ser considerada como educação. Deve-se reconhecer apenas que existem processos de aprendizagem e que eles têm certas características, como temos visto até aqui (UNIÃO EUROPEIA, 2000). A nosso ver, essa é uma discussão em aberto, que depende da definição de educação e de educação/aprendizagem informal utilizada. Numa perspectiva menos rígida e tendo em conta que as definições destas três categorias (F, NF, INF) são difusas e altamente dependentes do contexto, consideramos que, em geral, a informal pode ser chamada de educação, ou seja, em algum parâmetro ou fator haverá sempre algum grau de intencionalidade no processo.

\section{Fator 21: Medição dos resultados}

Na educação formal, os resultados são mensuráveis, em parte porque são previamente previstos e avaliados (RAMEY-GASSERT; WALBERG III; WALBERG, 1994). Há pouca margem para resultados não esperados e os que ocorrem não são considerados (GRIFFIN, 1994). É uma educação fechada e pouco flexível, como já visto em outros fatores.

Nesse fator apenas obtivemos referências de autores que consideram o binômio formalinformal. Pensamos que as suas definições se aplicam tanto ao não formal como ao informal, em diferentes graus. Os autores consideram que 0 fato de existirem muitos resultados inesperados e, portanto, ser difícil medir e avaliar esses resultados, é uma característica intrínseca da aprendizagem informal (WELLINGTON, 1990).

A educação não formal pode ser aqui incluída, mas com um maior grau de previsão. No entanto, sabe-se que, mesmo em pesquisas sobre resultados educativos em museus, há dificuldades em prever e medir resultados (COLLEY; HODKINSON; MALCOM, 2002), e, acrescentamos, esses cenários de educação não formal são provavelmente os mais organizados e sistematizados em termos de pesquisas e estudos de público.

\section{Frequência de utilização dos diferentes fatores e dimensões}

Sabemos que vários outros fatores terão ficado de fora, mas por meio da caracterização desses 21, agrupados em quatro dimensões, ficamos com um panorama geral dos principais pontos de distinção entre as educações formal, não formal e informal. Identificamos que cada uma das referências consultadas usa um conjunto diferente de fatores nas suas definições das tipologias educativas, dando ênfase a diferentes aspectos e não considerando outros. Olhando para o conjunto dos documentos, a tendência é as definições se basearem, ou pelo menos terem mais presentes, elementos relacionados com a dimensão estrutural, como pode ser visto na tabela com as médias de referências por fator ${ }^{2}$ em cada dimensão e para cada tipo educativo (Tabela 1).

\footnotetext{
2- Para cada dimensão e tipologia educativa, somaram-se as referências de todos os fatores e dividiu-se pelo número total de fatores na dimensão em causa. Os números de referências por fator encontram-se na Tabela 2.
} 
Tabela 1 - Média de referências por fator em cada uma das dimensões

\begin{tabular}{ccccc}
\hline & \multicolumn{3}{c}{ TIPOLOGIAS EDUCATIVAS } \\
\cline { 2 - 5 } DIMENSÕES & FORMAL & NÃO FORMAL & INFORMAL \\
CONTEÚDO & 4,6 & 4,4 & 2,8 \\
ESTRUTURA & 3,5 & 2,5 & 3 & 6,4 \\
PROPÓSITO & 11 & 5, & 5,7 & 3,5 \\
PROCESSO & 5,8 & $\vdots$ & 5 & 3 \\
\hline
\end{tabular}

Fonte: dados da pesquisa.

Enquanto que nas dimensões processo, conteúdo e propósito há médias entre 2,8 a 5,8 referências por fator, na dimensão estrutura chegamos a ter onze referências por fator, no caso da caracterização da educação formal. Há, então, um destaque claro dado aos fatores incluídos nesta dimensão.

A Tabela 2 lista o número de referências encontradas por fator e por tipo de educação ${ }^{3} \mathrm{e} o \mathrm{~s}$ totais por fator. Analisando os totais dos fatores individuais, são naturalmente os fatores estruturais os que têm mais referências por fator e por tipo de educação. Mas algumas outras dimensões estão também representadas no topo, como a intencionalidade, a determinação dos objetivos e a certificação (na dimensão propósitos), e a relação professor/aluno e mediação (na dimensão processo). A Tabela 3 mostra os oito fatores mais citados ${ }^{4}$ na literatura e o número médio de referências por tipo de educação.

Tabela 2 - Referências de autores distintos para cada fator, em cada tipologia educativa. As porcentagens são em relação ao total de artigos analisados (28).

\begin{tabular}{|c|c|c|c|c|c|c|c|c|}
\hline DIMENSÃO & Fatores & Formal & $\%$ & Não formal & $\%$ & Informal & $\%$ & $\begin{array}{c}\text { Total } \\
(\mathrm{F}+\mathrm{NF}+\mathrm{INF})\end{array}$ \\
\hline \multirow{8}{*}{ 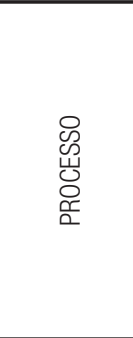 } & 1. Relação professor/aluno & 10 & 35,7 & 8 & 28,6 & 3 & 10,7 & 21 \\
\hline & 2. Avaliação & 7 & 25,0 & 3 & 10,7 & 2 & 7,1 & 12 \\
\hline & 3. Aprendizagem coletiva ou individual & 5 & 17,9 & 7 & 25,0 & 1 & 3,6 & 13 \\
\hline & 4. Abordagem pedagógica & 1 & 3,6 & 4 & 14,3 & 1 & 3,6 & 6 \\
\hline & 5. Mediação da aprendizagem & 8 & 28,6 & 6 & 21,4 & 5 & 17,9 & 19 \\
\hline & 6. Aprendizagem tácita ou explícita & 1 & 3,6 & 0 & 0,0 & 4 & 14,3 & 5 \\
\hline & 7. Aprendizagem contextual ou generalizável & 5 & 17,9 & 5 & 17,9 & 4 & 14,3 & 14 \\
\hline & 8. Papel das emoções & 0 & 0,0 & 2 & 7,1 & 2 & 7,1 & 4 \\
\hline \multirow{2}{*}{ CONTEÚDO } & 9. Natureza e tipo de conhecimento & 4 & 14,3 & 3 & 10,7 & 3 & 10,7 & 10 \\
\hline & 10. Estatuto do conhecimento & 3 & 10,7 & 2 & 7,1 & 3 & 10,7 & 8 \\
\hline \multirow{5}{*}{ 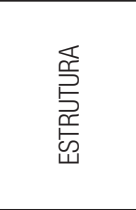 } & 11. Localização & 18 & 64,3 & 16 & 57,1 & 7 & 25,0 & 41 \\
\hline & 12. Grau de planejamento e de estrutura & 14 & 50,0 & 12 & 42,9 & 15 & 53,6 & 41 \\
\hline & 13. Determinação dos objetivos e resultados & 9 & 32,1 & 5 & 17,9 & 5 & 17,9 & 19 \\
\hline & 14. Duração/tempos da aprendizagem & 13 & 46,4 & 6 & 21,4 & 4 & 14,3 & 23 \\
\hline & 15. Tipos de grupos & 1 & 3,6 & 1 & 3,6 & 1 & 3,6 & 3 \\
\hline \multirow{6}{*}{$\begin{array}{l}\circ \\
\frac{}{5} \\
0 \\
0 \\
0 \\
\simeq\end{array}$} & 16. Intencionalidade do professor/aluno & 12 & 42,9 & 15 & 53,6 & 7 & 25,0 & 34 \\
\hline & 17. Certificação & 10 & 35,7 & 5 & 17,9 & 2 & 7,1 & 17 \\
\hline & 18. Interesses endereçados & 3 & 10,7 & 6 & 21,4 & 1 & 3,6 & 10 \\
\hline & 19. Objetivos da aprendizagem & 4 & 14,3 & 3 & 10,7 & 3 & 10,7 & 10 \\
\hline & 20. Estatuto educativo & 2 & 7,1 & 1 & 3,6 & 4 & 14,3 & 7 \\
\hline & 21. Medição dos resultados & 4 & 14,3 & 4 & 14,3 & 4 & 14,3 & 12 \\
\hline
\end{tabular}

Fonte: dados da pesquisa.

3- Soma de todos os autores distintos que referiram determinado fator na definição, explícita ou não, de cada uma das tipologias educativas. As referências encontram-se no Quadro 2.

4- Ver última coluna da Tabela 2. 
Tabela 3 - Total e média de referências dos oito fatores mais citados na literatura consultada

\begin{tabular}{|c|c|c|}
\hline FATOR & $\begin{array}{c}\text { Total refs } \\
\text { nos } 3 \text { tipos } \\
\text { (F, NF e INF) }\end{array}$ & $\begin{array}{l}\text { Média de } \\
\text { refs por tipo }\end{array}$ \\
\hline 11. Localização & 41 & 13,7 \\
\hline $\begin{array}{l}\text { 12. Grau de planejamento e de } \\
\text { estrutura }\end{array}$ & 41 & 13,7 \\
\hline $\begin{array}{l}\text { 16. Intencionalidade do professor/ } \\
\text { aluno }\end{array}$ & 34 & 11,3 \\
\hline $\begin{array}{l}\text { 14. Duração/tempos da } \\
\text { aprendizagem }\end{array}$ & 23 & 7,7 \\
\hline 1. Relação professor/aluno & 21 & 7,0 \\
\hline 5. Mediação da aprendizagem & 20 & 6,7 \\
\hline $\begin{array}{l}\text { 13. Determinação dos objetivos e } \\
\text { resultados }\end{array}$ & 19 & 6,3 \\
\hline 17. Certificação & 17 & 5,7 \\
\hline
\end{tabular}

Fonte: dados da pesquisa.

É interessante constatar que, apesar de ser referido por vários autores que a localização pode ser um fator ambíguo na distinção entre os tipos educativos, ele aparece como o mais citado pela maioria. Colocar a fronteira no espaço físico é talvez mais intuitivo e parece que definir pela estrutura, na maioria dos casos, é suficiente e mais simples.

\section{Algumas considerações}

Ao definir e categorizar as três principais tipologias educativas, tivemos sempre como foco a contribuição para o esclarecimento da área da educação não formal. Era nossa intenção explicitar ao longo do artigo que, "ela não deve ser vista, em hipótese alguma, como um tipo de proposta contra ou alternativa à educação formal, escolar" (GOHN, 2007, p. 14), e que "um dos grandes desafios da educação não formal tem sido defini-la, caracterizando-a pelo que ela é. Usualmente ela é definida pela negatividade - pelo que ela não é.” (GOHN, 2014, p. 39).

Além de ser uma área em fase de consolidação, portanto, conquistando seu espaço, percebemos por meio desta revisão que o seu universo "é já muito amplo e extraordinariamente variado" (TRILLA, 2004, p. 26). No documento de classificação da educação, a Unesco sublinha que

Dependendo do contexto nacional, a educação não formal pode abranger programas que contribuem para a alfabetização de jovens e adultos e educação para crianças fora da escola, bem como programas de habilidades para a vida, habilidades de trabalho e desenvolvimento social ou cultural. Pode incluir treinamento no local de trabalho para melhorar ou adaptar as qualificações existentes e competências, formação para desempregados ou inativos, bem como percursos educativos alternativos à educação formal e treinamento em alguns casos. Também pode incluir atividades de aprendizagem procuradas na busca por autodesenvolvimento [...] (UNESCO, 2011, p. 12).

De acordo com Trilla (2004), a educação não formal pode ser dividida em quatro âmbitos distintos: o do trabalho, o do lazer e cultura, o da educação social e o da própria escola. No contexto das pesquisas analisadas, verificamos que se sobressaem o âmbito da educação em museus e o da educação social. No primeiro, nota-se uma preocupação em definir o papel e competências dos mediadores (MARANDINO et al., 2004), em conhecer os públicos, os processos de aprendizagem nestes espaços específicos e, também, sua relação com o espaço escolar:

[...] os educadores e os profissionais de museus têm que entender que esses espaços são utilizados como acessórios para o processo formal educativo, mas que eles não têm este papel fundamental, embora muitas vezes o museu precise disso para ganhar mais dinheiro para se estruturar melhor. É importante entender que o museu deve ser percebido como um lugar onde é possível se ter a livre opção de se chegar lá e aprender. A partir desse movimento, há um tipo de aprendizagem para aquela pessoa (MCMANUS, 2013, p. 23). 
Já o âmbito da educação social, cuja principal pensadora no Brasil é a pesquisadora Maria da Glória Gohn, volta-se mais para o estudo do trabalho de ONGs e outras organizações relacionadas com as artes e a cultura. No livro sobre a educação não formal publicado em 2007, Não-fronteiras: universos da educação não formal, ela nos apresenta dados sobre os educadores, os públicos e as instituições e conclui, entre outras coisas, que há falta de apoios e "dificuldade de atuar em redes” (GOHN, 2007, p. 40). Mais recentemente, a mesma autora acrescenta que

[...] a nova realidade produzida pela ação de parcerias ou interação da sociedade civil organizada com órgãos públicos, empresas, ONGs etc. é pouco conhecida dos brasileiros e maioria das universidades enquanto instituição, assim como tem recebido pouca atenção dos pesquisadores e intelectuais de uma forma geral (GOHN, 2009, p. 40).

Há, portanto, muito caminho por andar, mas percebe-se que a educação não formal nesses espaços pode ter um papel importante no panorama educativo brasileiro e, também, mundial. Num outro trabalho, Gohn (2006b) aponta possíveis vias para percorrer esse caminho. As sugestões vão desde formação específica para os educadores e mediadores, definição dos objetivos e funções desta educação, sistematização das metodologias utilizadas e construção de novas ou "mapeamento das formas de educação não formal na autoaprendizagem dos cidadãos" (GOHN, 2006b, p. 31). Para esta autora, "o novo Brasil da educação não-formal representa fôlego renovado para as culturas esquecidas; esperança de aprendizagem para jovens carentes; diálogo social para a construção de saberes e abolição de preconceitos" (GOHN, 2007, p. 76).

A pesquisa aqui apresentada almejou contribuir para essa discussão com o esclarecimento dos termos usados para distinguir as diferentes tipologias educativas e perceber quais os fatores usados nas defınições das mesmas, procurando, assim, contribuir também para a estruturação e compreensão da área específica da educação não formal.

Percebemos que, no panorama educativo, há uma miriade de casos particulares distintos, mostrando a diversidade e riqueza de estratégias educativas que são possíveis nos dias de hoje. Como lembra Falk (2002, p. 2), "não há uma só maneira de aprender, nem um só lugar ou momento nos quais aprendemos. Toda aprendizagem tem um lugar contínuo, desde muitas fontes e de muitas maneiras diferentes". Mas tal diversidade constitui um desafio para os pesquisadores e agentes educativos na altura de classificar e definir as atividades, programas ou projetos em causa.

Constatamos, como já foi mostrado por outros autores, que não há uniformidade nas definições nem nos conjuntos de termos usados. Ainda assim, na maioria da literatura nacional a terminologia formal-não formal-informal é a mais utilizada. Tal prática está em sintonia com a opinião de Eshach (2007), quando afirma ser insuficiente e simplista englobar a educação ou aprendizagem que se desenvolve para além da educação formal em apenas um setor. Além disso, percebemos que as definições de informal da maioria dos autores que apenas distinguem entre formal e informal se aproximam muito das características descritas como definidoras do não formal nos autores que usam os três termos.

Expusemos também nesta investigação a dificuldade de se definir e estabelecer fronteiras entre as diferentes tipologias educativas (formal, não formal e informal). Por exemplo, já nos anos 80 do século passado, Belle (1982, p. 162) referia que "a escola alberga educação não formal através de atividades extracurriculares, que pouco têm a ver com créditos, notas ou diplomas, mas que refletem, de maneira deliberada e sistemática, ensino e aprendizagem". 0 contrário também acontece, pois "práticas formais podem ocorrer (e de fato ocorrem) em lugares como os museus, 
tidos como espaços de práticas não formais" (CAZELLI; COSTA; MAHOMED, 2010, p. 587).

Outro desafio enfrentado foi a quantidade de dimensões que se deve ter em conta quando da explicitação das definições. Investigamos mais de vinte fatores usados nas caracterizações dos diferentes sistemas educativos, mas apuramos que os autores referem principalmente fatores associados a características estruturais, como localização, grau de planejamento, duração, entre outros.

Rematamos sublinhando que "falar sobre aprendizagem e saber, fora das escolas do sistema regular de ensino de um país, implica em participar do amplo debate epistemológico sobre a produção de conhecimento no mundo contemporâneo" (GOHN, 2014, p. 35). Esperamos ter contribuído para esse debate e que este trabalho inspire outros, de modo que possamos aprofundar esse estudo, por exemplo, por meio da análise de mais literatura da área, pelo refinamento ou introdução de novos fatores, pela investigação das relações entre fatores usados conjuntamente, bem como pela construção de novos instrumentos para classificação dessas práticas educativas, baseados nesse conjunto de fatores ou dimensões.

\section{Referências}

ALVES, Denis Rogério Sanches; PASSOS, Marinez Meneghello; ARRUDA, Sergio de Mello. A educação não formal em periódicos da área de ensino de ciências no Brasil (1979-2008). Revista Brasileira de Ensino de Ciência e Tecnologia, Ponta Grossa, v. 3, n. 1, p. 16-40, jan./abr. 2010.

ANDERSON, David; LUCAS, Keith B.; GINNS, lan S. Theoretical perspectives on learning in an informal setting. Journal of Research in Science Teaching, v. 40, n. 2, p. 177-199, 2003.

BARDIN, Laurence. Análise de conteúdo. Lisboa: Edições 70, 2004.

BELLE, Thomas J. Formal, nonformal and informal education: a holistic perspective on lifelong education. International Review of Education, v. 28, p. 159-175, 1982.

BIZERRA, Alessandra; MARANDINO, Martha. A concepção de "aprendizagem" nas pesquisas em educação em museus de ciências. In: ENCONTRO NACIONAL DE PESQUISA EM EDUCAÇÃO EM CIÊNCIAS (ENPEC), 7., 2009, Florianópolis. Anais... Florianópolis: [s. n.], 2009. p. 1-12.

BRENNAN, Barrie Reconceptualizing non-formal education. International Journal of Lifelong Education, v. 16, n. 3, p. 185-200, 1997.

CAZELLI, Sibele; COSTA, Andréa Fernandes; MAHOMED, Carla. 0 que precisa ter um futuro professor em seu curso de formação para vir a ser um profissional de educação em museus? Ensino Em-Revista, Uberlândia, v. 17, n. 2, p. 579-595, 2010.

CHAGAS, Isabel. Aprendizagem não formal/formal das ciências: relações entre os museus de ciência e as escolas. Revista de Educação, Lisboa, v. 3, n. 1, p. 51-59, 1993.

COLLEY, Helen; HODKINSON, Phil; MALCOLM, Janice. Non-formal learning: mapping the conceptual terrain. A consultation report. Leeds: University of Leeds Lifelong Learning Institute, 2002.

ERAUT, Michael. Non-formal learning and tacit knowledge in professional work. British Journal of Educational Psychology, v. 70, p. 113-136, 2000.

ESHACH, Haim. Bridging in-school and out-of-school learning: formal, non-formal and informal education. Journal of Science Education and Technology, v. 16, n. 2, p. 171-190, 2007.

ETLLNG, Arlen. What is nonformal education? Journal of Agricultural Education, s/n, p. 72-76, 1993. Disponível em: <http:// pubs.aged.tamu.edu/jae/pdf/Vol34/34-04-72.pdf> Acesso em: jun. 2014.

FALK, John H. The contribution of free-choice learning to public understanding of science. Interciencia, Caracas, v. 27, n. 2, p. 1-8, 2002. 
GADOTTI, Moacir. A questão da educação formal/não-formal. In: Droit à l'education: solution à tous les problèmes ou problème sans solution? 2005, Institut internacional des droits de l'enfant, Sion. Anais... Sion: [s. n.], 2005. p. 1-11.

GOHN, Maria Glória. Educação não formal, aprendizagens e saberes em processos participativos. Investigar em Educação, Lisboa, II série, n. 1, p. 35-50, 2014.

GOHN, Maria Glória. Educação não-formal, educador(a) social e projetos sociais de inclusão social. Meta, Rio de Janeiro, v. 1, n. 1, p. 28-43, 2009.

GOHN, Maria Glória. Educação não-formal na pedagogia social. In: CONGRESSO INTERNACIONAL DE PEDAGOGIA SOCIAL, 1, 2006a, São Paulo. Anais... São Paulo [s. n.], 2006a. p. 1-10.

GOHN, Maria Glória. Educação não formal, participação da sociedade civil e estruturas colegiadas nas escolas. Ensaio, Rio de Janeiro, v. 14, n. 50, p. 27-38, 2006b.

GOHN, Maria Glória. Não-fronteiras: universos da educação não-formal. São Paulo: Itaú Cultural, 2007.

GRIFFIN, Janette. Learning to learn in informal science settings. Research in Science Education, v. 24, p. 121-128, 1994.

HEIMLICH, Joe E. Nonformal environment education: toward a working definition. The environment outlook. ERIC/CSMEE Informational Bulletin, p. 2-9, 1993.

KRIPPENDORFF, Klaus. Content analysis: an introduction to its methodology. London, UK: Sage, 1980. (The Sage context series; 5).

MARANDINO, Martha et al. A educação não formal e a divulgação científica: o que pensa quem faz? In: ENCONTRO NACIONAL DE PESQUISA EM ENSINO DE CIÊNCIAS (ENPEC), 4., 2004, Bauru. Atas... Bauru: ENPEC, 2004. Disponível em: <http://paje.fe.usp.br/ estrutura/geenf/textos/oquepensa_trabcongress05.pdf>. Acesso em: fev. 2014.

MARANDINO, Martha (Org.). Educação em museus: a mediação em foco. São Paulo: Geenf/ Feusp, 2008.

MARSICK, Victoria J.; WATKINS, Karen E. Informal and incidental learning. New Directions for Adult and Continuing Education, n. 89, p. 25-34, 2001.

MARTIN, Laura M. W. An emerging research framework for studying informal learning and schools. Science Education, v. 88, n. S1, p. 71-82, 2004

MCCALLIE, Ellen et al. Many experts, many audiences: public engagement with science and informal science education. A CAISE inquiry group report. Washington, D.C.: Center for Advancement of Informal Science Education, 2009. Disponível em: <http://caise. insci.org/uploads/docs/public_engagement_with_science.pdf>. Acesso em: jun. 2014.

MCMANUS, Paulette. Educação em museus: pesquisas e prática. São Paulo: Feusp, 2013.

PASSOS, Marinez Meneghello; ARRUDA, Sergio de Mello; ALVES, Denis Rogério Sanches Alves. Educação não formal no Brasil: 0 que apresentam os periódicos em três décadas de publicação (1979-2008). Revista Brasileira de Pesquisa em Educação em Ciências, Belo Horizonte, v. 12, n. 3, p. 131-150, 2012.

RAMEY-GASSERT, Linda; WALBERG, Herbert J. III; WALBERG, Herbert J. Reexamining connections: museums as science learning environments. Science Education, v. 78, n. 4, p. 345-363, 1994.

RENNIE, Léonie; STOCKLMAYER, Susan M. The communication of science and technology: past, present and future agendas. International Journal of Science Education, v. 25, n. 6, p. 759-773, 2003.

RESNICK, Lauren B. The 1987 presidential address: learning in school and out. Educational Researcher, v. 16, n. 9, p. $13-20,1987$.

RODARI, Paola. Learning science in informal environments: people, places and pursuits: a review by the US National Science Council. Journal of Science Communication, Trieste, v. 8, n. 3, p. 1-5, 2009. 
SEFTON-GREEN, Julian. Literature review in informal learning with technology outside school. Bristol [s. n.], 2004. (Futurelab series; Report 7).

TRILLA, Jaume B. La educación no formal y la ciudad educadora. In: CASANOVA, Hugo; LOZANO, Claudio (Ed.) Educación, universidad y sociedad: el vínculo crítico. Barcelona: Universitat de Barcelona, 2004. p. 16-42.

TRILLA, Jaume B. Aprender, lo que se dice aprender: una teoría alfabética de la educación. Barcelona: Octaedro, 1998.

UNESCO. International Standard Classification of Education - ISCED. Montreal; Quebec: Unesco: Institute for Statistics, 2011.

UNIÃO EUROPEIA. Comissão das Comunidades Europeias. Memorando sobre aprendizagem ao longo da vida. Bruxelas: [s. n.], 2000.

WELLINGTON, Jerry. Formal and informal learning in science: the role of the interactive science centres. Physics Education, v. 25, p. 247-252, 1990.

Recebido em: 07.07.2015

Aprovado em: 15.03.2016

Joana Brás Varanda Marques é licenciada em física pela Universidade de Coimbra, Portugal, mestre em educação pela Universidade Federal de São Carlos e doutoranda em educação na mesma universidade. Trabalhou no Sector de Educação do Museu da Ciência da Universidade de Coimbra durante cinco anos, sendo responsável pelo mesmo de 2010 a 2011.

Denise de Freitas é doutora em educação na área de didática e ensino de ciências pela Faculdade de Educação da Universidade de São Paulo (USP), com pós-doutorado na Faculdade de Ciências da Universidade de Lisboa (FC da UL). É professora associada do Departamento de Metodologia de Ensino da Universidade Federal de São Carlos (UFSCar). 